\title{
Analysis of the Genetic Polymorphism of Borrelia burgdorferi Sensu Lato by Multilocus Enzyme Electrophoresis
}

\author{
TIZIANO BALMELLI AND JEAN-CLAUDE PIFFARETTI* \\ Istituto Cantonale Batteriosierologico, 6904 Lugano, Switzerland
}

\begin{abstract}
In recent years, Borrelia burgdorferi sensu lato has been subdivided into three species, Borrelia burgdorferi sensu stricto, Borrelia garinii, and Borrelia afzelii, and a new species restricted to Japan, Borrelia japonica, has been isolated from Ixodes ovatus. In addition, members of several new genomic groups have been found in America and in Europe, suggesting that there are additional genospecies. In order to study the diversity of $B$. burgdorferi sensu lato, we analyzed 54 isolates cultured from humans and from different tick species and obtained from diverse geographic areas, including Europe, the United States, Japan, and the People's Republic of China. In order to investigate the genetic relationship between microorganisms that are transmitted by soft ticks and microorganisms that cause Lyme disease, we also included three strains of relapsing fever spirochetes. The method which we used was multilocus enzyme electrophoresis; 12 genetic loci were characterized on the basis of the electrophoretic mobilities of their products, and $\mathbf{5 0}$ distinct allele profiles (electrophoretic types) were distinguished. The mean genetic diversity per locus was 0.747 . A cluster analysis of a matrix of genetic distances for pairs of electrophoretic types revealed 11 divisions that were separated at genetic distances greater than 0.65 . Five of these divisions corresponded to $B$. burgdorferi sensu stricto, $B$. garinii, $B$. afzelii, $B$. japonica, and the newly proposed species "Borrelia andersonii." Our results also confirmed that there are two additional genomic groups in Europe and at least one additional group in the United States. The relapsing fever spirochetes were not clearly separated from the spirochetes associated with Lyme disease. In conclusion, we believe that the previously proposed subdivision of $B$. burgdorferi sensu lato into only four species should be reconsidered.
\end{abstract}

Lyme borreliosis is a multisystem disease that is caused by the spirochete Borrelia burgdorferi, which is transmitted to humans by the following ticks: Ixodes ricinus in Europe, Ixodes persulcatus in Asia, and Lxodes scapularis and Ixodes pacificus in North America. In about 60 to $80 \%$ of the infected patients, the illness begins with a local proliferation of microorganisms at the site of the tick bite, which leads to the first symptom of the disease, erythema chronicum migrans. Neurological or cardiac abnormalities, skin manifestations, or intermittent arthritis may follow erythema chronicum migrans. The late stage of the disease is characterized by chronic manifestations in joints, skin, and brains, such as arthritis, acrodermatitis chronica atrophicans, and neuroborreliosis, respectively (for a review see reference 45).

Since the first isolation of $B$. burgdorferi from the midgut of I. scapularis (18), a large number of strains have been recovered from both humans and ticks. The bacteria identified as $B$. burgdorferi constitute a heterogeneous group that is composed of several genomic species. Analyses of strains originating from various geographic areas resulted in subdivision of the former species $B$. burgdorferi ( $B$. burgdorferi sensu lato) into the following three species: $B$. burgdorferi sensu stricto, Borrelia garinii, and Borrelia afzelii $(12,15,19)$. Several groups of workers, including our group, have demonstrated that there is an association between these three species and the different chronic manifestations of Lyme disease. B. afzelii and B. garinii have been found to be associated with acrodermatitis chronica atrophicans and neuroborreliosis, respectively, and arthritis, which is the predominant late complication of the disease in

\footnotetext{
* Corresponding author. Mailing address: Istituto Cantonale Batteriosierologico, via Ospedale 6, 6904 Lugano, Switzerland. Phone: (004191) 92325 22. Fax: (004191) 92209 93. Electronic mail address: piffaret@cmu.unige.ch.
}

the United States, has been found to be associated with $B$. burgdorferi sensu stricto $(7,9,47)$.

Recently, it has been suggested that $B$. burgdorferi sensu lato includes additional species. A new, apparently nonpathogenic species, Borrelia japonica, was isolated from Ixodes ovatus and was found to be restricted to Japan. This species has been characterized by sodium dodecyl sulfate-polyacrylamide gel electrophoresis, pulsed-field gel electrophoresis, total DNADNA hybridization, ribotyping, and restriction fragment length polymorphism (RFLP) of the flagellin structural gene and the $16 \mathrm{~S}$ rRNA gene $(27,38)$. Until very recently, all three species described by Baranton et al. (12) were found in Europe, while in the United States B. burgdorferi sensu stricto was found almost exclusively, suggesting that the North American population is homogeneous compared with the heterogeneous European population. However, several atypical strains have now been isolated on both the east and west coasts of the United States and characterized $(4,5,17,31)$. The results of a PCR analysis of the fla gene suggested that some of these atypical strains belong to two new American genomic groups (8). This suggestion was confirmed by the results of an RFLP analysis of the intergenic space between the tandemly repeated $23 \mathrm{~S}(\mathrm{rrl})$ and 5S (rrf) rRNA genes (37). In the same report, several European strains were also identified as members of two additional genomic groups.

The purpose of this study was to determine the overall genetic relationships of $B$. burgdorferi sensu lato strains isolated in different parts of the world. Instead of the methods used most of the time to classify B. burgdorferi sensu lato strains, we used multilocus enzyme electrophoresis (MLEE), which is based on the polymorphism of a significant number of genes that encode housekeeping enzymes (and thus are selectively neutral) and not on a single chromosomal region. In this technique bacterial isolates are differentiated on the basis of variations in the electrophoretic mobilities of a large number of metabolic enzymes. The different electromorphs of each en- 
zyme reflect different alleles at the corresponding gene locus of the enzyme, and the electromorph profiles for a number of enzymes are identified as multilocus phenotypes (electrophoretic types [ETs]) which reflect chromosomal genotypes. Therefore, MLEE is a suitable tool for analyzing genetic diversity and for determining genetic distances between genotypes (44). Moreover, when MLEE is used to identify genomic groups, the results correlate well with the results of DNADNA hybridization $(12,16)$, which is considered the standard reference technique (48). In this paper we describe the results of an MLEE analysis of 54 B. burgdorferi sensu lato strains and three strains of relapsing fever spirochetes.

\section{MATERIALS AND METHODS}

Bacterial isolates. We analyzed 50 B. burgdorferi sensu lato strains (28 clinical isolates and 22 strains cultivated from different lxodes species) and five genetically characterized strains, including $B$. burgdorferi sensu stricto $\mathrm{B} 31^{\mathrm{T}}(\mathrm{T}=$ type strain), B. afzelii VS $461^{\mathrm{T}}, B$. garinii VS102 $(16,20,36)$, and B. japonica HO14 ${ }^{\mathrm{T}}$. In addition, we included in this study Borrelia parkeri M3001, Borrelia hermsii HS1, and Borrelia turicatae M2007 (Table 1). The origins of the strains were diverse and included Europe, the United States, Japan, and the People's Republic of China.

Cultures and preparation of lysates. Each Borrelia strain was grown in 2 liters of BSK-H medium (Sigma Chemical Co., St. Louis, Mo.) supplemented with $6 \%$ rabbit serum (Sigma) at $32^{\circ} \mathrm{C}$ until the color of the medium changed from red to yellowish. In order to avoid artifacts due to enzymatic proteolysis of dead cells that precipitated to the bottoms of the flasks, only the bacteria in the upper nine-tenths of each culture were harvested and centrifuged $\left(17,000 \times g, 4^{\circ} \mathrm{C}, 20\right.$ $\mathrm{min})$. The cells were washed twice in lysate buffer ( $10 \mathrm{mM}$ Tris, $1 \mathrm{mM}$ EDTA, 0.5 mM NADP [pH 6.8]), resuspended in $2 \mathrm{ml}$ of the same buffer, and disrupted by ultrasound treatment while they were cooled in ice (44). Cellular debris was removed by centrifugation at $20,000 \times g$ and $4^{\circ} \mathrm{C}$ for $30 \mathrm{~min}$, and the resulting supernatant was frozen and stored in $150-\mu \mathrm{l}$ aliquots at $-70^{\circ} \mathrm{C}$ until it was used.

Electrophoresis and enzyme staining. Bacterial lysates were thawed and subjected to gel electrophoresis under nondenaturing conditions in $10 \%$ starch gels as described by Selander et al. (44). Enzyme activities were detected on gels by using specific staining methods. We used the following 12 enzymes which exhibited demonstrable and interpretable activities for the MLEE analysis: Phe-L-Leu peptidase (PEP1), Leu-Leu-L-Leu peptidase (PEP2), Phe-L-Pro peptidase (PEP3), glyceraldehyde phosphate dehydrogenase (GP1), hexokinase (HEX), phosphoglucose isomerase (PGI), pyruvate kinase (PYK), triose phosphate isomerase (TPI), lactate dehydrogenase (LDH), mannose phosphate isomerase (MPI), 6-phosphogluconate dehydrogenase (6-PG), and esterase (EST). Electrophoresis for PEP1, PEP2, PEP3, GP1, HEX, PGI, PYK, TPI, and EST was performed with buffer system F (Tris-malate, pH 8.2), and electrophoresis for LDH, MPI, and 6-PG was performed with buffer system A (Tris-citrate, $\mathrm{pH} 8.0$ ). The staining methods used for PEP1, PEP2, PEP3, GP1, HEX, PGI, EST, LDH, MPI, and 6-PG were the staining methods described by Selander et al. (44), and the staining methods used for PYK and TPI were the methods described by Harris and Hopkinson (24).

Statistical analysis. A statistical analysis of the data was performed by using a computer program designed by T. S. Whittam and R. K. Selander. The genetic diversity $(h)$ at each enzyme locus was calculated as follows: $h=\left(1-\Sigma x_{i}^{2}\right)[n /(n$ $-1)$ ], where $x_{j}$ is the frequency of the $i$ th allele and $n$ is the number of ETs. The mean genetic diversity per locus was the arithmetic average of the $h$ values obtained for the locus. The genetic distance between two ETs was expressed as the proportion of loci at which dissimilar alleles occurred. The ET clusters were determined by using the average-linkage method and a matrix of pairwise coefficients of genetic distance (44).

\section{RESULTS}

Genetic diversity. All of the enzyme loci analyzed in this study except the EST locus were polymorphic; the EST locus was monomorphic (Tables 2 and 3 ). For the 12 enzymes analyzed, the number of alleles per locus ranged from 1 (EST) to 22 (PEP1), and the average number of alleles was 10.6. The genetic diversity at each locus was between 0.000 (the value for EST) and 0.925 (the value for PEP1) (Table 3). The mean genetic diversity for all of the loci was 0.747 . A total of 50 ETs were identified for the 57 strains which we studied (four strains exhibited ET 5, two strains exhibited ET 15, and four strains exhibited ET 42 [Table 1]). It should be pointed out that the ET numbers used in this study do not correspond to the num- bers used in our previous studies $(9,15)$ because one enzyme locus was replaced by two other loci and a different collection of strains was studied. The allele profiles of the ETs are shown in Table 2.

Cluster analysis and dendrogram. A cluster analysis of the 50 ETs in which the average-linkage method was used revealed 11 divisions (divisions I to XI [Fig. 1]) that were separated by genetic distances greater than 0.65 . Divisions I, II, VII, and VIII each contained a previously characterized strain of $B$. burgdorferi sensu stricto, $B$. garinii, $B$. afzelii, and $B$. japonica (strains $B 31^{\mathrm{T}}$ [ET 2], VS102 [ET 18], VS461 ${ }^{\mathrm{T}}$ [ET 28], and HO14 ${ }^{\mathrm{T}}$ [ET 41], respectively).

We found that, as determined by genetic distances, two strains of the relapsing fever spirochetes $B$. hermsii and $B$. parkeri (ETs 9 and 10) were more closely related to $B$. burgdorferi sensu stricto (genetic distances, 0.7 to 0.8 ) than to $B$. garinii and $B$. afzelii (genetic distances, $>0.8$ ). On the other hand, B. turicatae (ET 44), another relapsing fever spirochete, was more closely related to $B$. afzelii (genetic distance, 0.7 to 0.8 ) than to $B$. burgdorferi sensu stricto and $B$. garinii (genetic distances, $>0.8$ ).

\section{DISCUSSION}

Genetic structure of the $B$. burgdorferi sensu lato population. In a previous study, a collection of $B$. burgdorferi sensu lato strains was separated into three genomic groups by MLEE analysis (15). This result, together with the results of other genetic studies, contributed to the identification of $B$. burgdorferi sensu stricto, B. garinii, and B. afzelii (12). In this study, our analysis of a different population of strains revealed that there are additional groups. Our data are consistent with the results of a recent study in which the molecular polymorphism of a ribosomal intergenic space and total DNA-DNA hybridization were used; this study showed that there were four other genomic groups in addition to the four species described previously (37). Divisions I, II, VII, and VIII represent the four established species (B. burgdorferi sensu stricto, $B$. garinii, $B$. afzelii, and $B$. japonica, respectively), whereas the four genomic groups of Postic et al. (37) correspond to our divisions IV, V, IX, and XI. In addition, we identified division III containing ETs 19 through 21 (represented by three strains obtained from Japan, Russia, and Holland), division VI (represented by ET 27), and division X (represented by ET 48).

$B$. burgdorferi sensu stricto, B. garinii, and B. afzelii. B. burgdorferi sensu stricto, $B$. garinii, and $B$. afzelii are represented by divisions I, II, and VII, respectively. The genetic distances that separate these groups are consistent with data that were obtained by using a different collection of strains and a smaller number of enzyme loci (15). As reported previously, $B$. burgdorferi sensu stricto, $B$. garinii, and $B$. afzelii are preferentially associated with different chronic manifestations of Lyme disease $(7,9,47)$. Briefly, it appears that the first symptom of the disease, erythema chronicum migrans, is associated with all three of these species, whereas arthritis and acrodermatitis chronica atrophicans are caused by $B$. burgdorferi sensu stricto and $B$. afzelii, respectively, and neuroborreliosis occurs after infection by $B$. garinii or $B$. burgdorferi sensu stricto.

B. japonica. We confirmed that the recently described Japanese species $B$. japonica does exist (division VIII, ETs 41 through 43, in Fig. 1); this species is represented by six strains isolated from $I$. ovatus $(27,38)$.

None of the strains isolated from the patients with Lyme disease was identified as B. japonica, which is consistent with the apparent lack of pathogenicity in this species. Experimental infections of mice showed that B. japonica 0612 was less 
TABLE 1. B. burgdorferi sensu lato strains studied by the MLEE method

\begin{tabular}{|c|c|c|c|c|c|c|}
\hline Strain & ET & Division & Species & Biological origin & Geographic origin & Reference or source \\
\hline NY $13-87$ & 1 & I & B. burgdorferi sensu stricto & Skin & New York & 42 \\
\hline $\mathrm{B} 31^{\mathrm{T}}\left(=\operatorname{ATCC} 35210^{\mathrm{T}}\right)$ & 2 & I & B. burgdorferi sensu stricto & Ixodes dammini & New York & 18 \\
\hline A44S & 3 & I & B. burgdorferi sensu stricto & Skin & Holland & 47 \\
\hline VS219 & 4 & I & B. burgdorferi sensu stricto & I. ricinus & Switzerland & 36 \\
\hline P1G & 5 & I & B. burgdorferi sensu stricto & Knee & Switzerland & 41 \\
\hline IP2 & 5 & I & B. burgdorferi sensu stricto & $\operatorname{CSF}^{a}$ & France & 11 \\
\hline Pka & 5 & I & B. burgdorferi sensu stricto & Skin & Germany & 39 \\
\hline BE1 & 5 & I & B. burgdorferi sensu stricto & Knee & Switzerland & O. Péter \\
\hline IP3 & 6 & I & B. burgdorferi sensu stricto & $\mathrm{CSF}$ & France & 12 \\
\hline IP1 & 7 & I & B. burgdorferi sensu stricto & CSF & France & 2 \\
\hline GeHo & 8 & I & B. burgdorferi sensu stricto & Skin & Germany & 1 \\
\hline HS1 & 9 & & B. hermsii & O. hermsi & Washington & R. C. Johnson \\
\hline M3001 & 10 & & B. parkeri & O. parkeri & United States & R. C. Johnson \\
\hline Sika2 & 11 & II & B. garinii & I. persulcatus & Japan & 37 \\
\hline Sika1 & 12 & II & B. garinii & I. ovatus & Japan & 37 \\
\hline ECM $8^{h}$ & 13 & II & B. garinii & Skin & Sweden & 5 \\
\hline PD89 & 14 & II & B. garinii & Blood & People's Republic of China & G. Baranton \\
\hline 387 & 15 & II & B. garinii & CSF & Germany & 1 \\
\hline VSBP & 15 & II & B. garinii & $\operatorname{CSF}$ & Switzerland & 36 \\
\hline $\mathrm{P} / \mathrm{Bi}$ & 16 & II & B. garinii & CSF & Germany & 39 \\
\hline A76S & 17 & II & B. garinii & Skin & Holland & 47 \\
\hline VS102 & 18 & II & B. garinii & I. ricinus & Switzerland & 36 \\
\hline NT29 & 19 & III & $\mathrm{NA}^{c}$ & I. persulcatus & Japan & 23 \\
\hline Ip89 & 20 & III & NA & I. persulcatus & Russia & 23 \\
\hline A19S & 21 & III & NA & Skin & Holland & 47 \\
\hline PotiB1 & 22 & IV & NA & I. ricinus & Portugal & 37 \\
\hline PotiB3 & 23 & IV & NA & I. ricinus & Portugal & 37 \\
\hline PotiB2 & 24 & IV & NA & I. ricinus & Portugal & 37 \\
\hline VS116 & 25 & V & NA & I. nicinus & Switzerland & 36 \\
\hline UK & 26 & $\mathrm{~V}$ & NA & I. ricinus & England & 37 \\
\hline CA2 & 27 & VI & NA & Lxodes neotomae & California & 43 \\
\hline VS $461^{\mathrm{T}}$ & 28 & VII & B. afzelii & I. ricinus & Switzerland & 36 \\
\hline UO1 & 29 & VII & B. afzelii & Skin & Sweden & S. Bergström \\
\hline DK8 & 30 & VII & B. afzelii & Skin & Denmark & 29 \\
\hline A40S & 31 & VII & B. afzelii & Skin & Holland & 47 \\
\hline $\mathrm{P} /$ Sto & 32 & VII & B. afzelii & Skin & Germany & V. Preac-Mursic \\
\hline A45S & 33 & VII & B. afzelii & Skin & Holland & 47 \\
\hline A26S & 34 & VII & B. afzelii & Skin & Holland & 47 \\
\hline pko 2.85 & 35 & VII & B. afzelii & Skin & Germany & 39 \\
\hline ECM1 & 36 & VII & B. afzelii & Skin & Sweden & S. Bergström \\
\hline DK3 & 37 & VII & B. afzelii & Skin & Denmark & 30 \\
\hline PGAU & 38 & VII & B. afzelii & Skin & Germany & 1 \\
\hline ACA1 & 39 & VII & B. afzelii & Skin & Sweden & 6 \\
\hline $\mathrm{BO} 23$ & 40 & VII & B. afzelii & Skin & Germany & 1 \\
\hline $\mathrm{HO} 4^{\mathrm{T}}$ & 41 & VIII & B. japonica & I. ovatus & Japan & 27 \\
\hline F63B & 42 & VIII & B. japonica & I. ovatus & Japan & 27 \\
\hline COW 611A & 42 & VIII & B. japonica & I. ovatus & Japan & 27 \\
\hline COW 611C & 42 & VIII & B. japonica & I. ovatus & Japan & 27 \\
\hline O612 & 42 & VIII & B. japonica & I. ovatus & Japan & 27 \\
\hline Ika2 & 43 & VIII & B. japonica & I. ovatus & Japan & 27 \\
\hline M2007 & 44 & & B. turicatae & O. turicata & United States & R. C. Johnson \\
\hline DN127 & 45 & IX & NA & I. pacificus & California & 14 \\
\hline CA128 & 46 & IX & NA & I. neotomae & California & 17 \\
\hline CA55 & 47 & IX & NA & I. neotomae & California & 17 \\
\hline 25015 & 48 & $\mathrm{X}$ & NA & 1. dammini & New York & 4 \\
\hline 21123 & 49 & XI & NA & Ixodes dentatus & New York & 3 \\
\hline 19952 & 50 & XI & NA & I. dentatus & New York & 3 \\
\hline
\end{tabular}

${ }^{a} \mathrm{CSF}$, cerebrospinal fluid.

${ }^{b}$ This strain was described as a $B$. afzelii strain by Belfaiza et al. (13). However, these authors received the strain from two sources. By studying the RFLP of the intergenic space between the tandemly repeated 23S-5S rRNA genes, Baranton confirmed that the original isolate (which was the strain which we used) was a $B$. garinii strain $(10)$.

${ }^{c} \mathrm{NA}$, not associated with any species.

infective than $B$. garinii and $B$. afzelii (26). Thus, the laboratory data support the hypothesis that the pathogenicity of $B$. japonica is limited rather than the hypothesis that $I$. ovatus cannot transmit pathogenic borreliae to humans.
Is division III a subspecies of $B$. garinii? In a previous study, we examined different $B$. burgdorferi sensu lato strains isolated from patients having different symptoms of Lyme disease. One of the strains, strain A19S (isolated in Holland from the skin of 
TABLE 2. Allele profiles of 50 B. burgdorferi sensu lato ETs

\begin{tabular}{|c|c|c|c|c|c|c|c|c|c|c|c|c|}
\hline \multirow{2}{*}{ ET } & \multicolumn{12}{|c|}{ No. of alleles at the following enzyme loci: } \\
\hline & PEP1 & PEP2 & PEP3 & GP1 & PYK & PGI & HEX & TPI & LDH & MPI & 6-PG & EST \\
\hline 1 & 10 & 11 & 2 & 3 & 5 & 2 & 7 & 4 & 7 & 16 & 4 & 1 \\
\hline 2 & 10 & 11 & 9 & 3 & 5 & 2 & 7 & 3 & 7 & 14 & 4 & 1 \\
\hline 3 & 13 & 4 & 1 & 3 & 5 & 1 & 7 & 3 & 7 & 14 & 4 & 1 \\
\hline 4 & 15 & 10 & 2 & 3 & 2 & 1 & 7 & 4 & 7 & 14 & 4 & 1 \\
\hline $5^{a}$ & 15 & 10 & 2 & 3 & 5 & 1 & 7 & 4 & 7 & 14 & 4 & 1 \\
\hline 6 & 15 & 10 & 9 & 3 & 5 & 1 & 7 & 4 & 7 & 14 & 4 & 1 \\
\hline 7 & 6 & 10 & 2 & 3 & 5 & 1 & 7 & 4 & 7 & 14 & 4 & 1 \\
\hline 8 & 15 & 10 & 2 & 3 & 5 & 3 & 6 & 4 & 7 & 14 & 4 & 1 \\
\hline 9 & 3 & 11 & 11 & 0 & 8 & 1 & 6 & 7 & 7 & 17 & 7 & 1 \\
\hline 10 & 9 & 8 & 10 & 5 & 7 & 1 & 6 & 10 & 12 & 16 & 8 & 1 \\
\hline 11 & 4 & 5 & 7 & 2 & 3 & 5 & 3 & 5 & 2 & 5 & 2 & 1 \\
\hline 12 & 4 & 5 & 7 & 2 & 3 & 5 & 3 & 5 & 7 & 5 & 2 & 1 \\
\hline 13 & 5 & 5 & 9 & 2 & 3 & 5 & 3 & 4 & 6 & 5 & 2 & 1 \\
\hline 14 & 5 & 6 & 6 & 2 & 3 & 2 & 3 & 6 & 6 & 5 & 2 & 1 \\
\hline $15^{a}$ & 8 & 5 & 8 & 2 & 1 & 2 & 3 & 5 & 2 & 7 & 2 & 1 \\
\hline 16 & 8 & 5 & 9 & 2 & 1 & 2 & 3 & 5 & 2 & 7 & 2 & 1 \\
\hline 17 & 8 & 5 & 8 & 2 & 1 & 2 & 8 & 5 & 2 & 7 & 2 & 1 \\
\hline 18 & 6 & 1 & 4 & 2 & 1 & 2 & 3 & 4 & 6 & 13 & 4 & 1 \\
\hline 19 & 5 & 6 & 9 & 2 & 4 & 1 & 2 & 3 & 5 & 2 & 2 & 1 \\
\hline 20 & 1 & 6 & 9 & 2 & 4 & 1 & 2 & 3 & 5 & 3 & 2 & 1 \\
\hline 21 & 5 & 6 & 4 & 2 & 5 & 1 & 2 & 6 & 10 & 1 & 2 & 1 \\
\hline 22 & 2 & 4 & 2 & 1 & 2 & 1 & 1 & 5 & 6 & 10 & 3 & 1 \\
\hline 23 & 2 & 4 & 4 & 1 & 2 & 1 & 1 & 4 & 6 & 10 & 3 & 1 \\
\hline 24 & 2 & 4 & 2 & 1 & 2 & 1 & 4 & 5 & 6 & 11 & 7 & 1 \\
\hline 25 & 6 & 4 & 5 & 5 & 2 & 1 & 9 & 4 & 5 & 14 & 3 & 1 \\
\hline 26 & 17 & 1 & 4 & 5 & 1 & 1 & 9 & 4 & 5 & 9 & 3 & 1 \\
\hline 27 & 22 & 7 & 6 & 3 & 1 & 4 & 5 & 4 & 8 & 12 & 3 & 1 \\
\hline 28 & 17 & 4 & 3 & 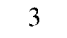 & 4 & 1 & 6 & 2 & 3 & 7 & 3 & 1 \\
\hline 29 & 17 & 4 & 3 & 3 & 4 & 1 & 6 & 2 & 3 & 7 & 1 & 1 \\
\hline 30 & 17 & 4 & 3 & 3 & 4 & 1 & 6 & 2 & 3 & 7 & 2 & 1 \\
\hline 31 & 20 & 4 & 3 & 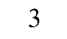 & 4 & 2 & 6 & 2 & 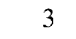 & 7 & 3 & 1 \\
\hline 32 & 17 & 4 & 4 & 3 & 4 & 1 & 6 & 2 & 3 & 9 & 3 & 1 \\
\hline 33 & 17 & 4 & 4 & 3 & 4 & 1 & 6 & 2 & 3 & 9 & 2 & 1 \\
\hline 34 & 20 & 4 & 2 & 3 & 4 & 1 & 6 & 2 & 3 & 9 & 3 & 1 \\
\hline 35 & 17 & 4 & 5 & 3 & 4 & 1 & 6 & 2 & 3 & 7 & 1 & 1 \\
\hline 36 & 17 & 4 & 5 & 3 & 4 & 1 & 6 & 2 & 3 & 7 & 3 & 1 \\
\hline 37 & 17 & 10 & 5 & 3 & 4 & 1 & 6 & 2 & 3 & 7 & 3 & 1 \\
\hline 38 & 17 & 4 & 5 & 3 & 4 & 1 & 6 & 2 & 1 & 7 & 3 & 1 \\
\hline 39 & 17 & 4 & 5 & 3 & 4 & 1 & 6 & 2 & 2 & 6 & 3 & 1 \\
\hline 40 & 17 & 4 & 4 & 3 & 4 & 1 & 6 & 0 & 3 & 8 & 4 & 1 \\
\hline 41 & 19 & 3 & 1 & 3 & 4 & 6 & 4 & 0 & 3 & 11 & 5 & 1 \\
\hline $42^{\prime \prime}$ & 19 & 3 & 1 & 3 & 4 & 6 & 0 & 8 & 3 & 13 & 5 & 1 \\
\hline 43 & 18 & 1 & 1 & 3 & 4 & 4 & 4 & 1 & 3 & 7 & 5 & 1 \\
\hline 44 & 7 & 9 & 9 & 3 & 6 & 2 & 4 & 9 & 11 & 11 & 9 & 1 \\
\hline 45 & 11 & 8 & 1 & 4 & 6 & 1 & 4 & 2 & 8 & 14 & 5 & 1 \\
\hline 46 & 14 & 8 & 1 & 4 & 6 & 1 & 2 & 2 & 8 & 12 & 5 & 1 \\
\hline 47 & 14 & 12 & 9 & 4 & 0 & 2 & 4 & 2 & 8 & 15 & 5 & 1 \\
\hline 48 & 21 & 2 & 4 & 4 & 4 & 3 & 5 & 2 & 9 & 4 & 5 & 1 \\
\hline 49 & 16 & 11 & 9 & 4 & 3 & 2 & 0 & 0 & 6 & 14 & 0 & 1 \\
\hline 50 & 12 & 11 & 1 & 4 & 3 & 2 & 0 & 2 & 4 & 14 & 6 & 1 \\
\hline
\end{tabular}

"More than one isolate exhibited this ET.

a patient), could not be included in any of the three known pathogenic species. Therefore, we suggested that a new pathogenic group exists (9). In this study, we found that two strains isolated from I. persulcatus (strains NT29 [ET 19] and Ip89 [ET 20]) belonged to the same division as strain A19S (ET 21), division III, which was separated from the $B$. garinii division by a genetic distance of 0.74 . The position of two strains NT29 and Ip89 is controversial. While Postic et al. (37) identified these organisms as B. garinii strains on the basis of DNA-DNA hybridization data, Fukunaga et al. (23) showed that they exhibited a different rRNA gene RFLP pattern than the other $B$. garinii isolates, which supports our observations. In two addi- tional studies, workers in Fukunaga's group $(22,34)$ showed that other Japanese isolates obtained from patients with Lyme disease clustered in the same RFLP group as strains NT29 and Ip89. Since DNA hybridization is considered the standard reference technique for bacterial classification (48), division III strains must be considered members of $B$. garinii. However, there may be sufficient evidence to give division III subspecies status.

Two genomic species restricted to Europe. The five division IV and V strains (ETs 22 through 26) were all isolated from the European tick I. ricinus. The genetic distances $(>0.75)$ that separate these divisions from the other divisions are consistent with the results of the DNA-DNA hybridization experiments performed by Postic et al. (37); the strains belonging to groups PotiB2 (division IV) and VS116 (division V) of Postic et al. were found to exhibit less than $70 \%$ DNA relatedness and $\Delta T_{m}$ values of $7.0^{\circ} \mathrm{C}$ or higher with the four established $B$. burgdorferi sensu lato species $\left(\Delta T_{m}\right.$ is the difference between the melting temperature of a homologous hybrid and the melting temperature of a heterologous hybrid). It has been proposed that strain VS116 (ET 25) should be the reference strain for a new group on the basis of the polymorphism of its outer surface proteins (OspA and OspB) (36).

Heterogeneity of American isolates. In contrast to European isolates, American B. burgdorferi sensu lato strains have been considered homogeneous for a long time $(12,15)$. However, several authors have described atypical strains isolated on the west and east coasts of the United States. The differences between these strains and other American isolates have been assessed by different methods $(14,29,38,40,49,50)$. On the basis of the results of a fla gene PCR assay, an RFLP analysis of a 5S-23S rRNA intergenic spacer amplicon, and DNA-DNA hybridization, a large number of American isolates that differ from $B$. burgdorferi sensu stricto have been included in two new genomic species, designated groups DN127 and $21123(8,37)$. Recently, on the basis of the results of rRNA studies, the name "Borrelia andersonii" was proposed for genomic group 21123 (33). Our results support the hypothesis that these two genomic species, represented in our study by divisions IX (group DN127) and XI (group 21123, "B. andersonii"), are present in the United States.

In our study, two other American strains (strains CA2 and 25015 [ETs 27 and 48, respectively]) appeared to represent two distinct divisions (divisions VI and $\mathrm{X}$, respectively [Fig. 1]). Although the level of relatedness between strains CA2 (division VI) and 21123 (division XI) was borderline (level of DNA

TABLE 3. Numbers of alleles and levels of genetic diversity at 12 enzyme loci of Borrelia species

\begin{tabular}{ccc}
\hline Enzyme locus & No. of alleles & Genetic diversity \\
\hline PEP1 & 22 & 0.925 \\
PEP2 & 12 & 0.846 \\
PEP3 & 11 & 0.888 \\
GP1 & 6 & 0.673 \\
PYK & 9 & 0.802 \\
PGI & 6 & 0.610 \\
HEX & 10 & 0.846 \\
TPI & 11 & 0.810 \\
LDH & 12 & 0.854 \\
MPI & 17 & 0.886 \\
6-PG & 10 & 0.827 \\
EST & 1 & 0.000 \\
& & \\
Mean & 10.6 & 0.747 \\
\hline
\end{tabular}




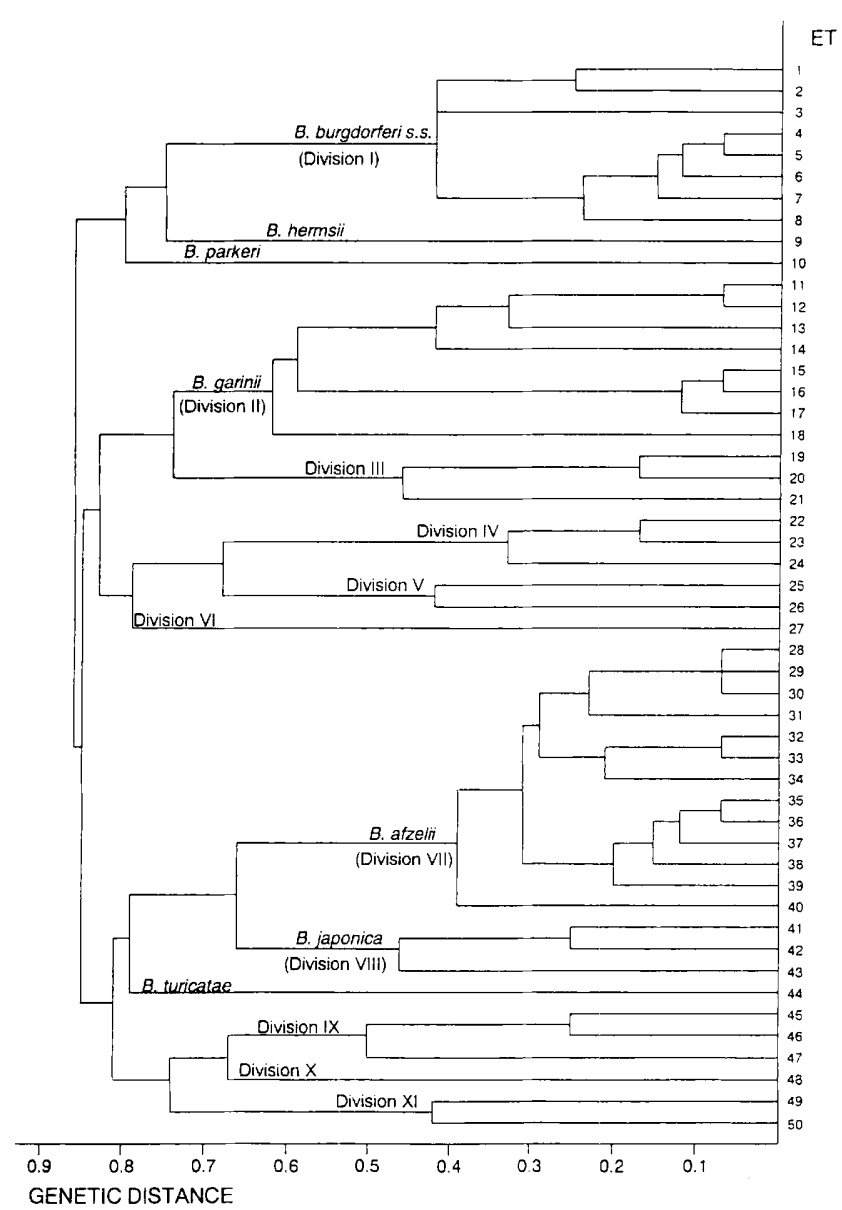

FIG. 1. Genetic relationships among 50 ETs of B. burgdorferi sensu lato and relapsing fever spirochetes, based on electrophoretically demonstrable allelic variations at 12 enzyme loci. The dendrogram was generated by using the average-linkage method of clustering and a matrix of pairwise coefficients of genetic distance.

relatedness, $73 \% ; \Delta T_{m}, 5.0^{\circ} \mathrm{C}$ ), Postic et al. (37) classified both of these strains in the same genomic group (group 21123). In contrast, we estimated that the genetic distance between these divisions was 0.95 . This finding is supported by other data obtained in our laboratory, which, on the basis of the results of a nucleotide sequence alignment of the $h b b$ histone-like protein, identified strain $\mathrm{CA} 2$ as a member of a new genomic group that is clearly separated from representatives of group 21123 (division XI) (46).

Although the results of DNA hybridization experiments placed strain 25015 (division X, ET 48) in group DN127 (division IX) (37), our results showed that the genetic distance between these divisions was 0.67 . Data obtained with other genetic techniques (46) placed strain 25015 at the border of division IX.

Relapsing fever spirochetes. The taxonomy of Borrelia species associated with relapsing fever has not been properly investigated yet. In humans, Lyme borreliosis and relapsing fever present different clinical pictures and are transmitted by members of two different tick families, the hard ticks (Ixodidae, mostly Ixodes spp.) and the soft ticks (Argasidae, mostly Ornithodoros spp.), respectively (28). However, such a subdivision might be arbitrary. Fukunaga has isolated a relapsing fever Borrelia strain (Borrelia miyamotae sp. nov.) from the hard tick I. persulcatus (21). In Bergey's Manual of Systematic Bacteriology
(28), the borreliae were classified into species on the basis of their arthropod vectors. For instance, $B$. hermsii, $B$. turicatae, and $B$. parkeri are transmitted only by the specific tick vectors Ornithodoros hermsi, Ornithodoros turicata, and Ornithodoros parkeri, respectively. However, on the basis of the results of DNA-DNA hybridization experiments, it has been suggested that these three species constitute a single species (25). Our MLEE data suggest that these three relapsing fever spirochetes represent three distinct species that are separated at genetic distances greater than 0.75 .

Surprisingly, on our dendrogram the relapsing fever spirochetes clustered with the different genomic groups and species of Lyme disease agents (B. burgdorferi sensu lato) (Fig. 1). This finding is supported by the results of a recent study (32) that was based on an analysis of fatty acid methyl esters and showed that borreliae associated with Lyme disease could not be distinguished as a group from the relapsing fever spirochetes. However, Noppa et al. (35) sequenced the flagellin gene of different Borrelia species and showed that the Lyme disease species were evolutionarily more closely related to each other than to relapsing fever Borrelia species (B. hermsii and Borrelia crocidurae). In order to assess the exact relationship between these two groups of borreliae (the soft- and hard-tick spirochetes), more strains will have to be analyzed by different molecular genetic methods.

Conclusions. The main purpose of this study was to investigate the genetic structure of the $B$. burgdorferi sensu lato population. It seems clear that the previous subdivision of these microorganisms into only four species should be reconsidered. Our results confirmed the existence of the recently described species $B$. japonica and the recently proposed species " $B$. andersonii." Furthermore, they suggested that there are two additional genomic groups in Europe and at least one additional genomic group in the United States. We believe that promotion of these new genomic groups to Borrelia species status will be supported by the discovery of specific phenotypic characteristics for each of them. One may wonder whether the results generated by MLEE or other similar analyses faithfully reflect evolutionary history or whether they are the consequence of a genetic method that is far too sensitive. MLEE has been used successfully for many years to analyze the genetic structures of eukaryotic and bacterial populations $(24,44)$. An important property of MLEE is that it takes into account many chromosomal loci that encode housekeeping enzymes, which are considered selectively neutral. Thus, the conclusions inferred from MLEE results are based on a panel of genes that represent the chromosome as a whole and not on a single gene or a unique region of the genome. In general, MLEE results are compatible with the results of DNA-DNA hybridization, a method still considered the standard reference technique in bacterial species identification $(12,16,48)$.

\section{ACKNOWLEDGMENTS}

We thank G. Baranton (Paris, France), O. Péter (Sion, Switzerland), and A. P. van Dam (Amsterdam, Holland) for supplying Borrelia strains, C. Valsangiacomo (Lugano, Switzerland) and G. Baranton for helpful discussions, and R. Epstein (Geneva, Switzerland) for revising the manuscript.

This work was supported by grant 31-36566.92 from the Swiss Foundation for Scientific Research.

\section{REFERENCES}

1. Adam, T., G. S. Gassmann, C. Rasiah, and U. B. Gobel. 1991. Phenotypic and genotypic analysis of Borrelia burgdorferi isolates from various sources. Infect. Immun. 59:2579-2585.

2. Allal, J., P. Thomas, C. Vieyres, J. Mazzonelli, and G. Baranton. 1986. La 
maladie de Lyme. Isolement d'une Borrelia dans le liquide céphalorachidien. Med. Mal. Infect. 16:445-446.

3. Anderson, J. F., L. A. Magnarelli, R. B. LeFebvre, T. G. Andreadis, J. B. McAninch, G. C. Perng, and R. C. Johnson. 1989. Antigenically variable Borrelia burgdorferi isolated from cottontail rabbits and lxodes dentatus in rural and urban areas. J. Clin. Microbiol. 27:13-20.

4. Anderson, J. F., L. A. Magnarelli, and J. B. McAninch. 1988. New Borrelia burgdorferi antigenic variation isolated from Ixodes dammini from upstate New York. J. Clin. Microbiol. 26:2209-2212.

5. Asbrink, E., and A. Hovmark. 1985. Successful cultivation of spirochetes from skin lesions of patients with erythema chronicum migrans Afzelius and acrodermatitis chronica atrophicans. Acta Pathol. Microbiol. Immunol. Scand. Sect. B 93:161-163.

6. Asbrink, E., A. Hovmark, and B. Hederstedt. 1984. The spirochetal etiology of acrodermatitis chronica atrophicans Herxheimer. Acta Dermato-Venereol. 64:506-512.

7. Assous, M. V., D. Postic, G. Paul, P. Névot, and G. Baranton. 1993. Western blot analysis of sera from Lyme borreliosis patients according to the genomic species of the Borrelia strains used as antigens. Eur. J. Clin. Microbiol. Infect. Dis. 12:261-268.

8. Assous, M. V., D. Postic, G. Paul, P. Névot, and G. Baranton. 1994. Individualisation of two genomic groups among American Borrelia burgdorferi sensu lato strains. FEMS Microbiol. Lett. 121:93-98.

9. Balmelli, T., and J.-C. Piffaretti. 1995. Association between different clinical manifestations of Lyme disease and different species of Borrelia burgdorferi sensu lato. Res. Microbiol. 146:329-340.

10. Baranton, G. Personal communication.

11. Baranton, G., P. Perolat, Y. Dufresne, D. Postic, R. Quentin, and B. Fouquet. 1989. Isolement de Borrelia burgdorferi du liquide céphalorachidien. Presse Med. 18:637.

12. Baranton, G., D. Postic, I. Saint Girons, P. Boerlin, J.-C. Piffaretti, M. Assous, and P. A. D. Grimont. 1992. Delineation of Borrelia burgdorferi sensu stricto, Borrelia garinii sp. nov., and group VS 461 associated with Lyme borreliosis. Int. J. Syst. Bacteriol. 42:378-383.

13. Belfaiza, J., D. Postic, E. Bellenger, G. Baranton, and I. Saint Girons. 1993. Genomic fingerprinting of Borrelia burgdorferi sensu lato by pulsed-field gel electrophoresis. J. Clin. Microbiol. 31:2873-2877.

14. Bisset, M. L., and W. Hill. 1987. Characterization of Borrelia burgdorfer strains isolated from Ixodes pacificus ticks in California. J. Clin. Microbiol. 25:2296-2301.

15. Boerlin, P., O. Péter, A. G. Bretz, D. Postic, G. Baranton, and J.-C. Piffaretti 1992. Population genetic of Borrelia burgdorferi isolates by multilocus enzyme electrophoresis. Infect. Immun. 60:1677-1683.

16. Boerlin, P., J. Rocourt, F. Grimont, P. A. D. Grimont, C. Jacquet, and J.-C. Piffaretti. 1992. Listeria ivanovii subsp. londoniensis subsp. nov. Int. J. Syst. Bacteriol. 42:69-73.

17. Brown, R. N., and R. S. Lane. 1992. Lyme disease in California: a nove enzootic transmission cycle of Borrelia burgdorferi. Science 256:1439-1442.

18. Burgdorfer, W., A. G. Barbour, S. F. Hayes, J. L. Nenach, E. Gruwldt, and J. P. Davies. 1982. Lyme disease: a tick borne spirochetosis? Science 216: 1317-1319.

19. Canica, M. M., F. Nato, L. du Merle, J. C. Mazie, G. Baranton, and D. Postic. 1993. Monoclonal antibodies for identification of Borrelia afzelii $\mathrm{sp}$ nov. associated with late cutaneous manifestations of Lyme borreliosis. Scand. J. Infect. Dis. 25:441-448.

20. Filipuzzi-Jenni, E., M. Blot, N. Schmid-Berger, J. Meister-Turner, and J. Meyer. 1993. Genetic diversity among Borrelia burgdorferi isolates: more than three genospecies. Res. Microbiol. 144:295-304.

21. Fukunaga, M. Personal communication.

22. Fukunaga, M., M. Sohnaka, M. Nakao, and K. Miyamoto. 1993. Evaluation of genetic divergence of borrelial isolates from Lyme disease patients in Hokkaido, Japan, by rRNA gene probes. J. Clin. Microbiol 31:2044-2048.

23. Fukunaga, M., M. Sohnaka, and Y. Yanagihara. 1993. Analysis of Borrelio species associated with Lyme disease by rRNA gene restriction fragment polymorphism. J. Gen. Microbiol. 139:1141-1146.

24. Harris, H., and D. A. Hopkinson. 1976. Handbook of enzyme electrophoresis in human genetics. American Elsevier Publishing Co., Inc., New York.

25. Hyde, F. W., and R. C. Johnson. 1984. Genetic relationship of Lyme disease spirochetes to Borrelia, Treponema, and Leptospira spp. J. Clin. Microbiol. 20:151-154.

26. Ishii, N., E. Isogai, H. Isogai, K. Kimura, T. Nishikawa, N. Fujii, and H. Nakajima. T cell response to Borrelia garinil, Borrelia afzelii, and Borrelia japonica in various congenic mouse strains. Microbiol. Immunol., in press.

27. Kawabata, H., T. Masuzawa, and Y. Yanagihara. 1993. Genomic analysis of Borrelia japonica sp. nov, isolated from Lxodes ovatus in Japan. Microbiol. Immunol. 37:843-848.

28. Kelly, R. T. 1984. Spirochaetales, p. 57-61. In N. R. Krieg and J. G. Holt (ed.), Bergey's manual of systematic bacteriology, vol. 1 . The Williams \& Wilkins
Co., Baltimore.

29. Kurashige, S., M. Bisset, and L. Oshiro. 1990. Characterization of a tick isolate of Borrelia burgdorferi that possesses a major low-molecular-weight surface protein. J. Clin. Microbiol. 28:1362-1366.

30. Lebech, A. M., and K. Hansen. 1992. Detection of Borrelia burgdorferi DNA in urine samples and cerebrospinal fluid samples from patients with early and late Lyme neuroborreliosis by polymerase chain reaction. J. Clin. Microbiol. 30:1646-1653.

31. Liveris, D., A. Gazumyan, and I. Schwartz. 1995. Molecular typing of Borrelia burgdorferi sensu lato by PCR-restriction fragment length polymorphism analysis. J. Clin. Microbiol. 33:589-595.

32. Livesley, M. A., I. P. Thompson, L. Gern, and P. A. Nuttall. 1993. Analysis of intra-specific variation in the fatty acid profiles of Borrelia burgdorferi. $\mathrm{J}$. Gen. Microbiol. 139:2197-2201.

33. Marconi, R. T., D. Liveris, and I. Schwartz. 1995. Identification of novel insertion elements, restriction fragment length polymorphism patterns, and discontinuous 23S rRNA in Lyme disease spirochetes: phylogenetic analysis of rRNA genes and their intergenic spacers in Borrelia japonica sp. nov. and genomic group 21038 (Borrelia andersonii sp. nov.) isolates. J. Clin. Microbiol. 33:2427-2434.

34. Nakao, M., K. Miyamoto, and M. Fukunaga. 1994. Lyme disease spirochetes in Japan: enzotic transmission cycles in birds, rodents, and Ixodes persulcatus ticks. J. Infect. Dis. 170:878-882.

35. Noppa, L., N. Burman, A. Sadziene, A. G. Barbour, and S. Bergström. 1995. Expression of the flagellin gene in Borrelia is controlled by an alternative $\sigma$ factor. Microbiology (Washington, D.C.) 141:85-93.

36. Peter, O., and A. G. Bretz. 1992. Polymorphism of outer surface proteins of Borrelia burgdorferi as a tool for classification. Zentralbl. Bakteriol. Parasitenkd. Infektionskr. Hyg. Abt. 1 Orig. 277:28-33.

37. Postic, D., M. V. Assous, P. A. D. Grimont, and G. Baranton. 1994. Diversity of Borrelia burgdorferi sensu lato evidenced by restriction fragment length polymorphism of $r f(5 S)-r r l$ (23S) intergenic amplicons. Int. J. Syst. Bacteriol. 44:743-752.

38. Postic, D., J. Belfaiza, E. Isogai, I. Saint Girons, P. A. D. Grimont, and G. Baranton. 1993. A new genomic species in Borrelia burgdorferi sensu lato isolated from Japanese ticks. Res. Microbiol. 144:467-473.

39. Preac-Mursic, V., B. Wilske, and G. Schierz. 1986. European Borrelia burgdorferi isolated from humans and ticks: culture conditions and antibiotic susceptibility. Zentralbl. Bakteriol. Parasitenkd. Infektionskr. Hyg. Abt. 1 Orig. Reihe A susceptibility. 263:112-118.

40. Ralph, D., D. Postic, G. Baranton, C. Pretzman, and M. McClelland. 1993. Species of Borrelia distinguished by restriction site polymorphism in $16 \mathrm{~S}$ rRNA genes. FEMS Microbiol. Lett. 111:239-244.

41. Schmidli, J., T. Hunziker, P. Moesli, and U. B. Schaad. 1988. Cultivation of Borrelia burgdorferi from joint fluid three months after treatment of facial palsy due to Lyme borreliosis. J. Infect. Dis. 158:905-906.

42. Schwan, T. G., W. Burgdorfer, and C. F. Garon. 1988. Changes in infectivity and plasmid profile of the Lyme disease spirochete, Borrelia burgdorferi, as a result of in vitro cultivation. Infect. Immun. 56:1831-1836.

43. Schwan, T. G., M. E. Schrumpf, R. H. Karstens, J. R. Clover, J. Wong, M. Daugherty, M. Struthers, and P. A. Rosa. 1993. Distribution and molecular analysis of Lyme disease spirochetes, Borrelia burgdorferi, isolated from ticks throughout California. J. Clin. Microbiol. 31:3096-3108.

44. Selander, R. K., D. A. Caugant, H. Ochman, J. M. Musser, M. N. Gilmour and T. S. Whittam. 1986. Methods of multilocus enzyme electrophoresis for bacterial population genetics and systematics. Appl. Environ. Microbiol. 51 873-884.

45. Steere, A. C. 1989. Lyme disease. N. Engl. J. Med. 321:586-596.

46. Valsangiacomo, C., T. Balmelli, and J.-C. Piffaretti. Manuscript in preparation.

47. van Dam, A. J., H. Kuiper, K. Vos, A. Widjojkusumo, B, M, de Jongh, L. Spanjaard, A. C. P. Ramselaar, D. M. Kramer, and J. Dankert. 1993 Different genospecies of Borrelia burgdorferi are associated with distinct clinical manifestations of Lyme disease. Clin. Infect. Dis. 17:708-717.

48. Wayne, L. G., D. J. Brenner, R. R. Colwell, P. A. D. Grimont, O. Kandler M. I. Krichevsky, L. H. Moore, W. E. C. Moore, R. G. E. Murray, E. Stackebrandt, M. P. Starr, and H. G. Trüper. 1987. Report of the Ad Hoc Committee on Reconciliation of Approaches to Bacterial Systematics. Int. J. Syst. Bacteriol. 37:463-464.

49. Welsh, J., C. Pretzman, D. Postic, I. Saint Girons, G. Baranton, and M. McClelland. 1992. Genomic fingerprinting by arbitrarily primed polymerase chain reaction resolves Borrelia burgdorferi into three distinct phyletic groups. Int. J. Syst. Bacteriol. 42:370-377.

50. Zinge, B. C., J. F. Anderson, R. C. Johnson, and R. B. LeFebvre. 1993 Comparative analysis of genetic variability among Borrelia burgdorferi isolates from Europe and the United States by restriction enzyme analysis, gene restriction fragment length polymorphism, and pulsed-field gel electrophoresis. J. Clin. Microbiol. 31:3115-3122. 